\title{
SOBRE LA CONCEPCIÓN DE LA TRAGEDIA EN BIZANCIO. IGNACIO EL DIÁCONO, VERSOS SOBRE ADÁN
}

\author{
Pablo A. Cavallero \\ UBA-UCA-Conicet, Argentina
}

Resumen: En el marco de un estudio general de la evolución de la tragedia como género desde la época clásica hasta Bizancio, se edita y traduce aquí la obra Versos sobre Adán y se añade un estudio filológico orientado a demostrar que el texto es una 'tragedia', no en la concepción clásica del género sino en su vertiente bizantina.

Palabras-clave: Bizancio - tragedia - Ignacio el Diácono - drama religioso - Adán

\section{ABOUT THE CONCEPTION OF THE TRAGEDY IN BYZANTIUM. IGNATIUS DEACON, VERSES ABOUT ADAM}

Abstract: Within the framework of a general study about the evolution of the tragedy as genre from the classical period to Byzantium, here it is edited and translated the work Verses about Adam; and it is added a philological study oriented to demonstrate that this text is a 'tragedy', no under the classic conception of the genre but under his Byzantine aspect.

Key-words: Byzantium - tragedy - Ignatius Deacon - religious play - Adam

Recibido: 27.03.2014 - Aceptado: 21.04.2014

\section{Correspondencia: Pablo A. CAVAllero}

Email: pcavalle@filo.uba.ar pablo.a.cavallero@gmail.com

Doctor en Letras. Profesor titular regular de Lengua y cultura griegas. Investigador en el Consejo Nacional de Investigaciones Científicas. Director de la Sección Filología Medieval del Instituto de Filología Clásica (Facultad de Filosofía y Letras, Universidad de Buenos Aires).

Miembro de número de la Academia Argentina de Letras. Instituciones: Universidad de Buenos Aires - CONICET - Universidad Católica Argentina Dirección particular: Helguera 4445, C 1419 CUK Buenos Aires Dirección laboral: Puan 480, 1406 Buenos Aires. 
$\mathrm{E}$ 1 objetivo de este trabajo es presentar un texto bizantino supuestamente dramático y analizar en qué medida él puede responder al concepto de 'tragedia', en el marco de un estudio general sobre la evolución de la tragedia después del período clásico hasta Bizancio.

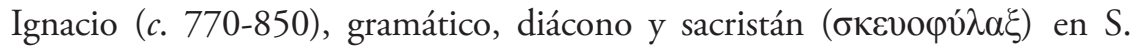
Sabiduría de Constantinopla, luego Obispo de Nicea y finalmente monje ${ }^{1}$, de quien da una noticia la Suda, iconoclasta arrepentido, compuso en el siglo Ix dos textos hagiográficos (de los patriarcas Tarasio ${ }^{2}$, su maestro, y Nicéforo, muerto éste en 828), ambos con referencias clásicas y patrísticas y forma retórica; unos epigramas $(A P \text { 15: 29-31, 39)3 })^{3}$, elegías fúnebres 4 , sesenta y cuatro cartas y dos obras en 'yambos bizantinos', es decir, en dodecasílabos, conocidas como Contra Tomás el rebelde (+ 823 perdida) y Versos sobre Adán 5 . Esta última está conservada en la $P G$ 117: 1164-74 (1894), donde Migne toma la edición de Boissonade (Anecdota Graeca 1, 1829, 436-444) ${ }^{6}$, la cual fue consultada, comparándola con el mismo códice BN Paris 1630, ff. 213-4, por F. Dübner al incluirla Wagner en

${ }^{1}$ Se discute si "Ignacio el diácono" e "Ignacio el monje" son la misma persona. El criticado libro de COTTAS dedica a la obra algunas referencias descriptivas (1931: 162-3). Apenas alguna mención y alusión aparecen en el crítico y sarcástico artículo de LA PIANA (1936: 172-3, 201). Para BROWNING (1968: 408) son la misma persona.

${ }^{2}$ Patriarca entre el 25/12/784 y el 25/2/806. Nicéforo lo fue entre 806 y 815 . Estos textos datarían de 846 y 838 respectivamente, según WOLSKA-CONUS (1970).

${ }^{3}$ Cf. DE BOOR (1888). Para KRUMBACHER (1897: 720) estos textos corresponden a otro autor, Ignacio el monje.

${ }^{4} P G$ 11: 1173-6.

${ }^{5}$ Para más detalles, cf. KAZHDAN (1999: 343-366). Hay unos Versos sobre Lázaro que algunos atribuyen a Ignacio diácono y otros a Ignacio patriarca, muerto en 877 . Asimismo, son de dudosa autoría unos Cánones sobre Tarasio, Nicéforo y los mártires de Amorío, los relatos hagiográficos Vida de Gregorio de Decápolis y Vida de Jorge de Amástride, la Colección de veinticuatro sentencias yámbicas alfabéticas, la Paráfrasis de Esopo. Véase también EFTHYMIADIS (2011: 1045). BROWNING (1968: 404 y 408) destaca una Monodia anacreóntica al alumno Pablo, al que alude también $A P$ 15: 30, que probaría el ejercicio de Ignacio como profesor de escuela patriarcal.

${ }^{6}$ Aclara MIGNE: "Anno incerto Ignatii Diaconi Drama de primi parentis lapsu”. 
sus Fragmenta Euripidis, en el sector dedicado a Christus patiens, Ezechieli et christianorum poetarum reliquiae dramaticae, pp. 91-94, del ańo 1846.

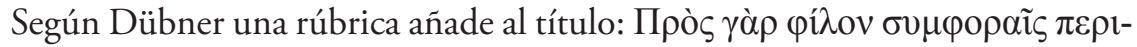

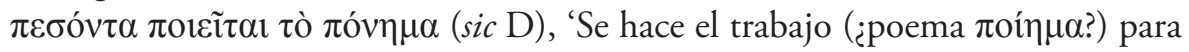
un amigo caído en desgracias'.

Los Versos sobre Adán son una composición de ciento cuarenta y tres líneas -Müller (1886: 32) opinó que debían de ser ciento cincuenta- inspirada en el Génesis en el pasaje bíblico del relato del pecado original. Los personajes que dialogan son la serpiente, Eva, Adán y Dios.

Para Cantarella (2010: 579), quien acompaña el texto, solamente desde el v. 55, con una versión italiana, es una obra retórica destinada a la lectura, al igual que el Christus patiens ${ }^{7}$, y que sigue la tradición de los dramas bíblicos como la Exagogé de Ezequiel. En estos casos, como ocurre con Alejandra de Licofrón y con los Mimos de Herondas, la discusión sobre la representación será eterna; pero en realidad, nada impide que haya sido representado. Mientras que para WolskaConus (1970: 330) es "un raro ejemplo de drama religioso bizantino", para Kazhdan (1999: 346) considerarlo drama "es probablemente una exageración”.

En otro lugar hemos realizado un estudio filológico sobre las familias de $\tau \rho \alpha-$ $\gamma \omega \delta i ́ \alpha$ y de $\tau \rho \alpha \gamma o v ́ \delta$. Hemos concluido que:

a) el canto, el componente 'lírico' que Dimitrakos ${ }^{8}$ señala como de origen dorio (Aristóteles, Poética 3,5), tuvo siempre un gran peso, tanto que, más allá de los cambios que la tragedia pudo tener en tanto 'drama' o 'representación teatral', siempre se mantuvo como ingrediente;

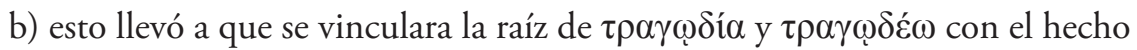
de 'cantar', aplicación que se registra ya en autores del siglo iv (Basilio, Juan Crisóstomo, Macario);

c) pero el 'canto' no perteneciente a la 'tragedia' debía ser diferenciado del propio de ella; de ahí que se adoptó para la acepción amplia una pequeña variante fonética: $\tau \rho \alpha \gamma o v-$ en vez de $\tau \rho \alpha \gamma \omega$-, aparentemente desde la baja Edad Media bizantina;

\footnotetext{
${ }^{7}$ Así también opina KRUMBACHER (1897: 717), LA PIANA (1936: 171), para citar solamente a algunos.

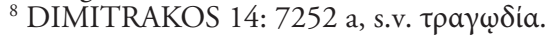


d) esta distinción, paralela a la conservación de la forma $\tau \rho \alpha \gamma \omega-$, destaca que no hubo una sustitución semántica en esta forma, sino la creación de un término similar que permitiera la traslación del campo 'canto de tragedia' al campo 'canto en general', pero sin anular el primero; de tal modo, éste sigue existiendo y sigue teniendo un referente real;

e)la cuestión es, pues, determinar si ese "referente real", es decir, la tragedia como drama o representación teatral, se mantuvo en las etapas bizantina y neohelénica como mera realidad 'académica', como una reposición de obras secularmente clásicas o además como una realidad vital, creativa e incluso diferente de la "tragedia griega clásica".

En este sentido, el texto de Ignacio puede servir como objeto de análisis. Para ello presentamos nuestra propia edición del texto, teniendo en cuenta las previas ( $\mathrm{B}=$ Boissonade; $\mathrm{D}=$ Dübner; $\mathrm{M}=$ Müller; $\mathrm{PG}=$ Migne $)$, $\mathrm{y}$ una traducción. Incluimos una propuesta de Cantarella quien, en lo demás, se atiene a Dübner. En el texto, en v. 119 mantenemos la forma $\delta \varepsilon \imath \lambda i \tilde{\omega} v \tau \alpha$ como modificador de un femenino, interpretando que se trata de un participio cristalizado. En v. 130

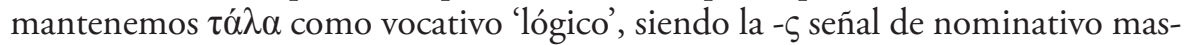
culino y la $-v$ del tema puede caer, análogo a $\mu \varepsilon ́ \gamma \alpha$ según Hesiquio T 43: 1; así se registra, además, en varios casos de versos dodecasílabos: Christus patiens 330; Teodoro Estudita Epigramas 33: 9; Cristóbal de Mitilena Carmina varia 36: 25, 109: 49; Nicolás IV Muzalo Versus de abdicatione 783; Simeón el nuevo teó-

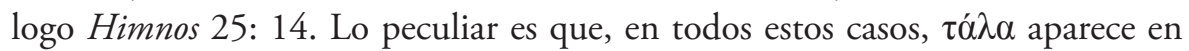
posición final de verso, mientras que aquí no.

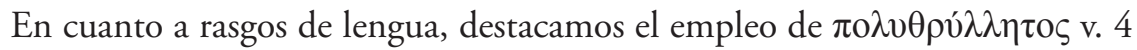
donde se hace geminación, si bien le -v- es larga por naturaleza; de $\pi \rho \circ \beta$ ov́ $\lambda$ เov v. 23, que aparece registrado en Sophoclés con el sentido de 'previa consulta'; $\tau \varepsilon \tau \rho \alpha ́ \kappa \lambda v \sigma \tau 0 \zeta$ v. 34, que parece un hápax; también aparece غ̇ம́v v. 143, forma épico-arcaica, que, como ह̌ $\omega \varsigma$, responde a necesidades métricas; y potentialis sin

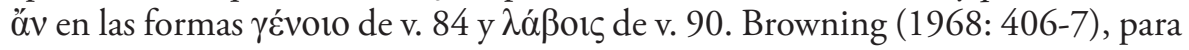
quien Ignacio pudo ser quien puso en circulación el drama clásico, señala ecos de la tragedia antigua, que indicamos en nota?

En el aparato no incluimos las diferencias de puntuación con las otras ediciones. Entre corchetes remitimos a las páginas de Dübner y Müller y a las columnas de Migne.

9 También señala "préstamos más generales de la lengua de la tragedia" en los versos 1, 3, 19, 35, $46,52,56,63,73$ y 125. 


\section{ITNATIOY $\Sigma$ TIXOI EI $\Sigma$ TON A $\Delta A M$}

[PG 1164 D; M 28]

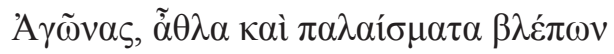

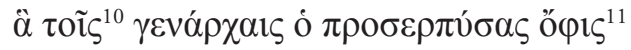

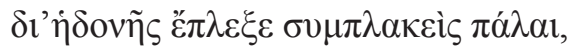

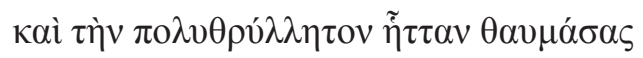

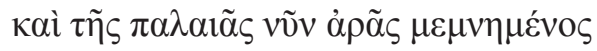

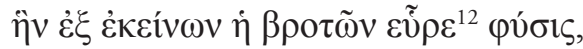

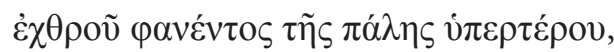

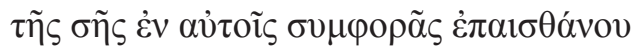

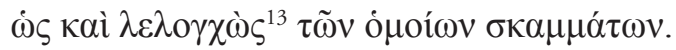

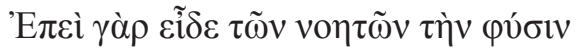
10

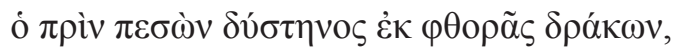

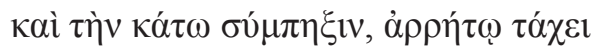

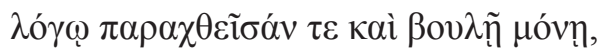

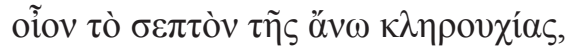

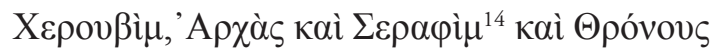

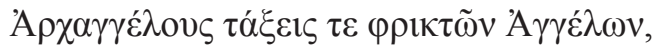

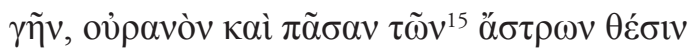

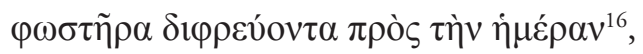

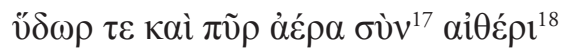

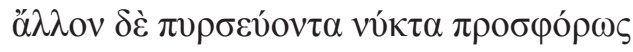

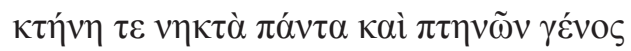

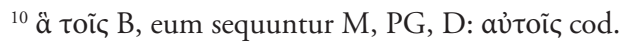

${ }^{11}$ ö $\varphi ı$ addidit B; eum sequuntur M, PG, D.

${ }^{12} \varepsilon \tilde{\text { p }} \varepsilon v \mathrm{M}, \mathrm{PG}$.

${ }^{13} \lambda \varepsilon \lambda$ о $\chi \chi \grave{\omega} \varsigma$ B, D, M, PG: $\lambda \varepsilon \lambda$ oux $\grave{\omega} \varsigma$ cod.

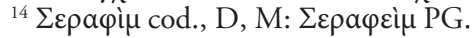

${ }^{15} \tau \tilde{\omega} \nu$ cod., D, M: $\tau \grave{\eta} \nu$ B, PG.

${ }^{16} \mathrm{Vv}$. 18-19 cod.: in ordine 19-18 B, D, M, PG. Desunt duo versus, secundum D.

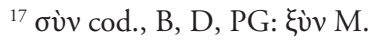

${ }^{18}$ ai $\theta \dot{\varepsilon} \rho ı$ edd.: ai $\theta \dot{\varepsilon} \rho \varepsilon ı$ cod.
} 


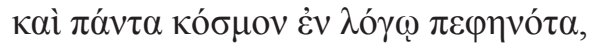

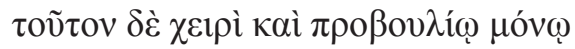

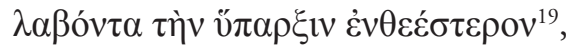

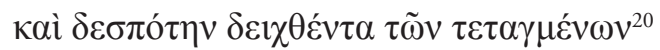

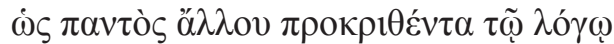

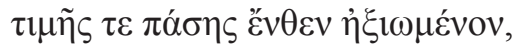

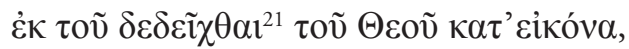

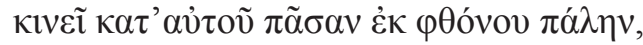

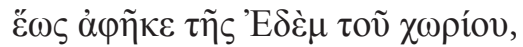

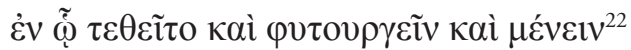

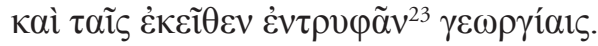

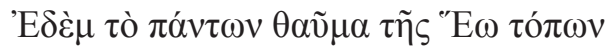

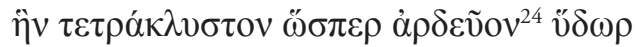

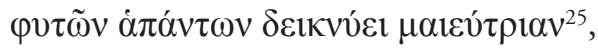

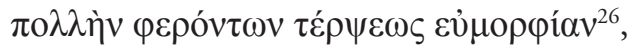

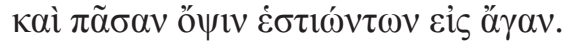

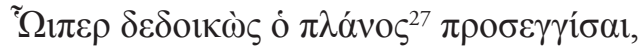

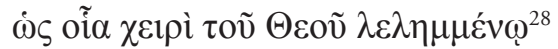

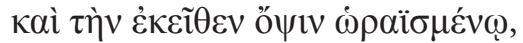

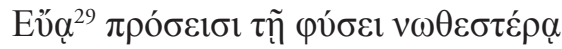

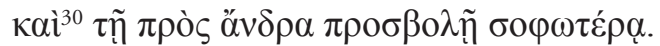

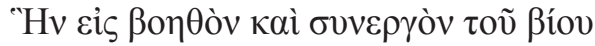

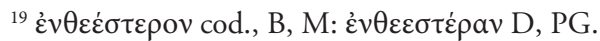

${ }^{20} \tau \varepsilon \tau \alpha \gamma \mu \varepsilon \dot{\varepsilon} \nu \omega \nu$ cod., edd.: "fort. $\tau \varepsilon \tau \nu \gamma \mu \varepsilon \dot{v} \omega \nu$ " notat M.

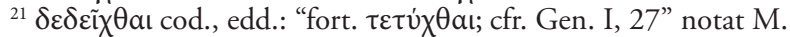

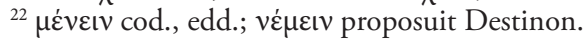

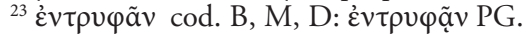

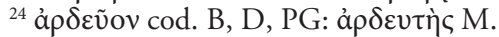

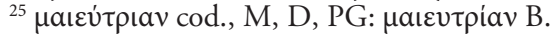

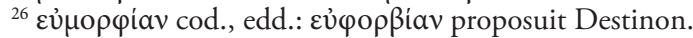

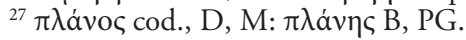

${ }^{28} \lambda \varepsilon \lambda \eta \mu \mu \varepsilon \dot{\varepsilon} \omega$ cod., B, D, PG: $\delta \varepsilon \delta \mu \eta \mu \varepsilon \dot{v} \omega \omega$ M, $\pi \varepsilon \pi \lambda \alpha \sigma \mu \varepsilon \dot{v} \nu \omega$ proposuit D.

${ }^{29}$ Eủa edd.: Eṽa cod.

${ }^{30}$ kaì cod., edd.: koủ M proposuit.
} 


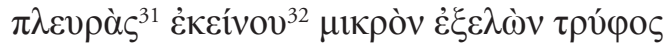

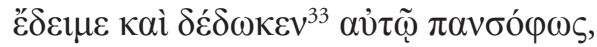

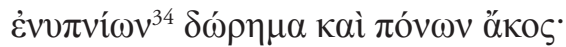

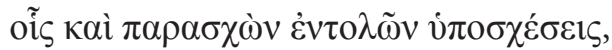

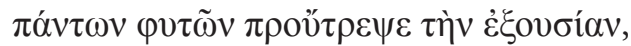

[PG 1168]

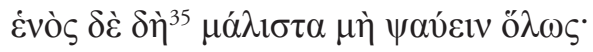

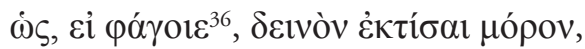

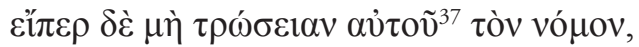

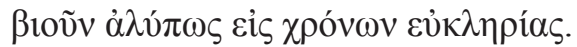

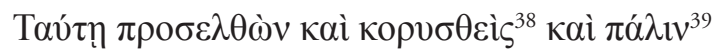

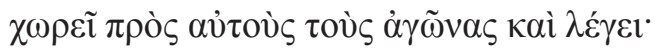

\section{ОФІ $\Sigma$ :}

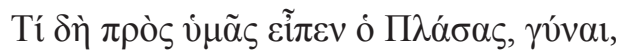

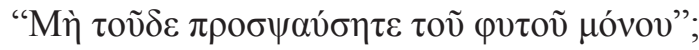

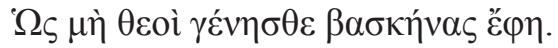

\section{EYA:}

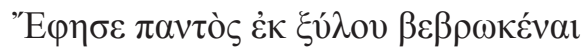

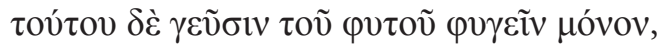

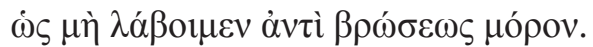

\section{ОФІ $\Sigma$ :}

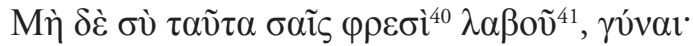

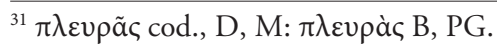

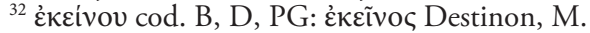

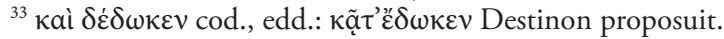

${ }^{34} \dot{\varepsilon} v v \pi v i \omega v$ cod. B, PG: $\dot{\varepsilon} v u ́ \pi v i o v$ D, M.

${ }^{35} \delta \grave{\varepsilon} \delta \grave{\eta} \mathrm{D}, \mathrm{M}: \delta \dot{\varepsilon}$ cod., $\delta \dot{\varepsilon} \omega \grave{\omega} \mathrm{B}, \mathrm{PG}$ cum hiato.

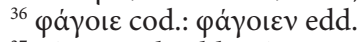

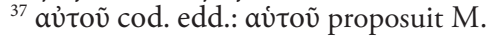

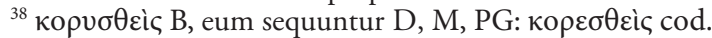

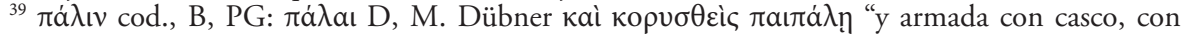

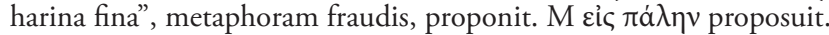

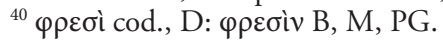

${ }^{41} \lambda \alpha \beta o \tilde{~ c o d}$., edd.: $\beta \alpha \lambda$ oṽ proposuit M. 


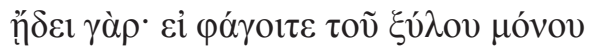

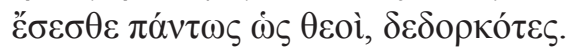

EYA:

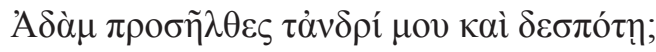

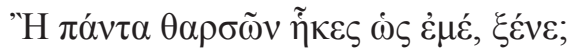

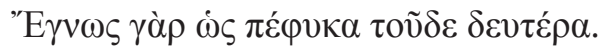

\section{ОФІ $\Sigma$ :}

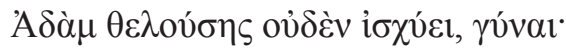

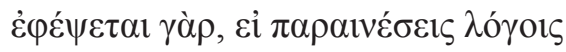

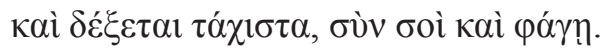

EYA:

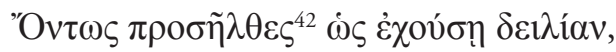

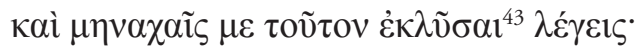

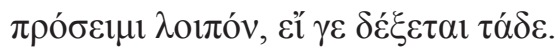

\section{ОФІГ:}

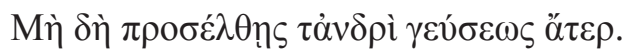

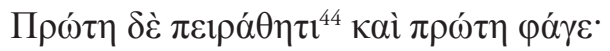

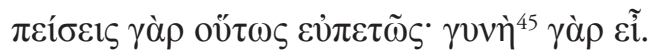

EYA:

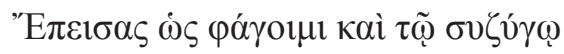

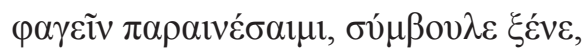

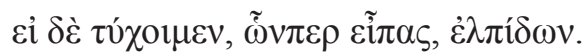

\section{ОФІГ:}

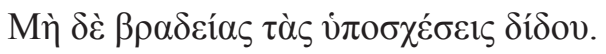

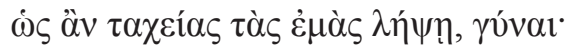

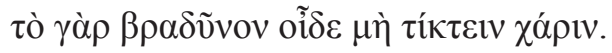

\footnotetext{
${ }^{42} \pi \rho \circ \sigma \tilde{\eta} \lambda \theta$ cod., cum duplici compendio $\varepsilon \varsigma / o v$.

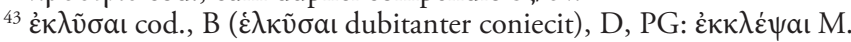

${ }^{44} \pi \varepsilon \iota \rho \dot{a} \theta \eta \tau \iota$ cod., B, D, PG: $\pi \varepsilon \iota \rho a \theta \tilde{\eta} \tau \iota$ M.

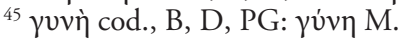


EYA:

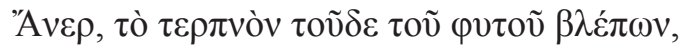

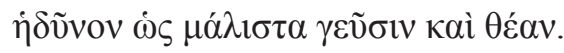

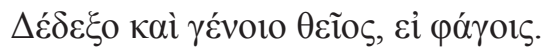

$\mathrm{A} \triangle \mathrm{AM}$ :

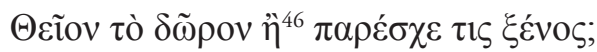

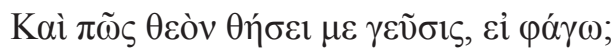

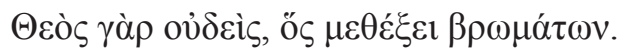

\section{EYA:}

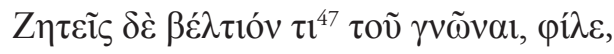

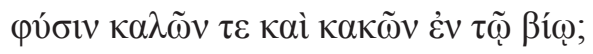

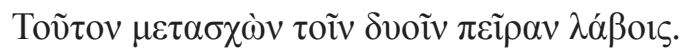

\section{$\mathrm{A} \triangle \mathrm{AM}$ :}

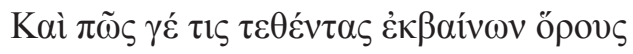

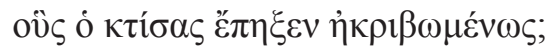

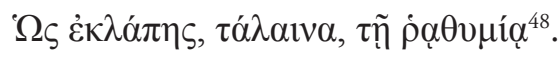

\section{EYA:}

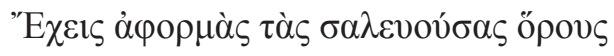

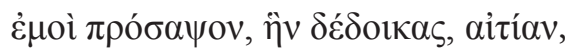

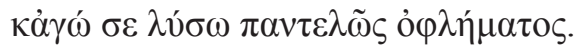

\section{$\mathrm{A} \triangle \mathrm{AM}$ :}

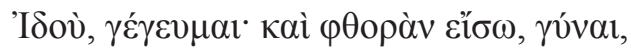

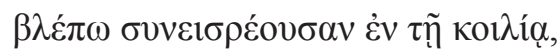

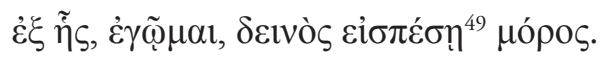

\footnotetext{
${ }^{46}$ ì Cantarella: $\varepsilon \grave{~ c o d ., ~ B, ~ D, ~ M, ~ P G . ~}$

${ }^{47} \tau \mathrm{\tau}$ addidit $\mathrm{B}$, eum sequuntur $\mathrm{D}, \mathrm{M}, \mathrm{PG}$.

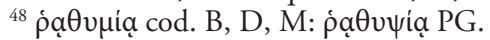

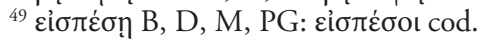


EYA:

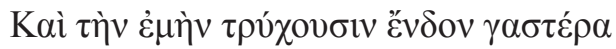

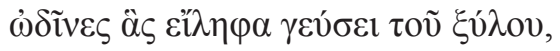

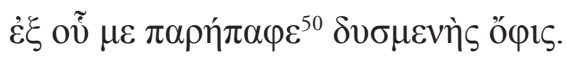

$\mathrm{A} \triangle \mathrm{AM}$ :

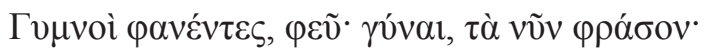

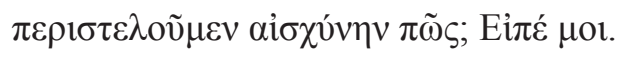

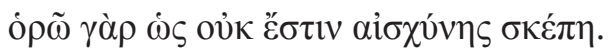

EYA:

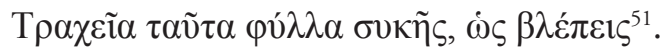

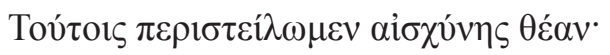

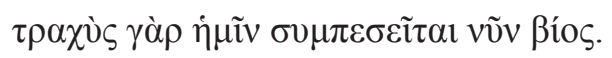

\section{$\mathrm{A} \triangle \mathrm{AM}$ :}

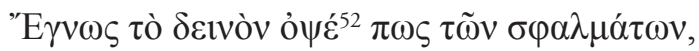

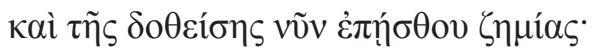

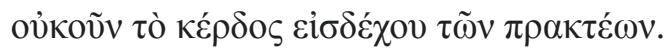

EYA:

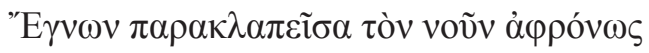

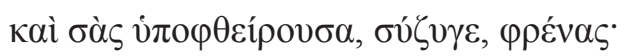

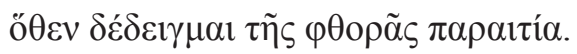

$\mathrm{A} \triangle \mathrm{AM}:$

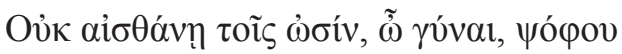

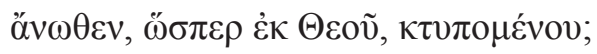

[D 94]

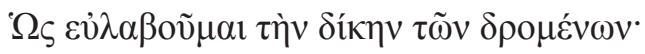

EYA:

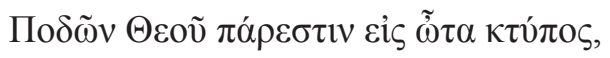

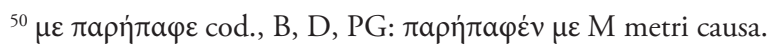

${ }^{51} \beta \lambda \dot{\epsilon} \pi \varepsilon เ \varsigma$ B, D, M, PG: $\beta \lambda \varepsilon$ cod.

52 ỏ $\psi \dot{\varepsilon}$ cod., B, D, PG: ő $\psi \varepsilon$ M. 


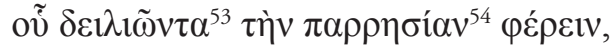

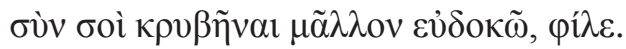

$\mathrm{A} \triangle \mathrm{AM}$ :

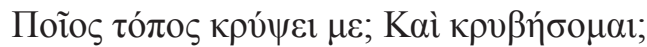

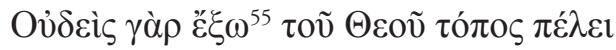

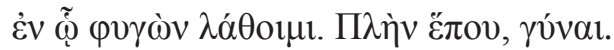

\section{$\Theta \mathrm{EO} \Sigma$ :}

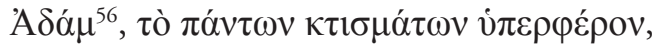

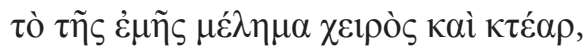

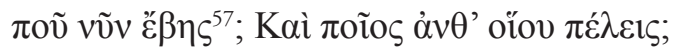

$\mathrm{A} \triangle \mathrm{AM}:$

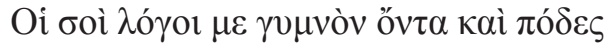

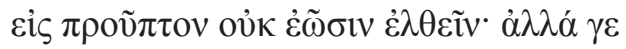

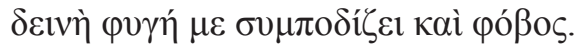

\section{$\Theta \mathrm{EO} \Sigma$ :}

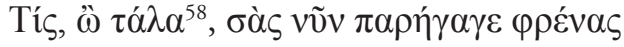

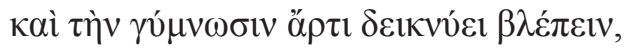

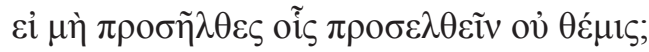

\section{$\mathrm{A} \triangle \mathrm{AM}$ :}

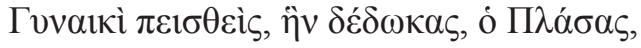

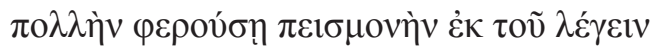

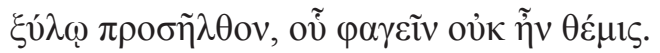

\section{$\Theta \mathrm{EO} \Sigma$ :}

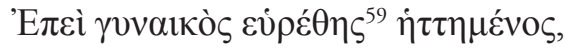

\footnotetext{
${ }^{53} \delta \varepsilon \iota \lambda \iota \tilde{\omega} v \tau \alpha \operatorname{cod} .: \delta \varepsilon \iota \lambda \iota \tilde{\omega} \sigma \alpha$ B, D, M, PG.

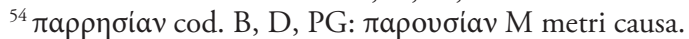

${ }^{55} \varepsilon \bar{\xi} \xi \omega \operatorname{cod} . \mathrm{B}, \mathrm{D}, \mathrm{M}$ : $\check{\varepsilon} \xi \omega \mathrm{PG}$.

${ }_{56}$ A $\delta$ á $\mu$ cod., B, M: Ađđà $\mu$ D, PG.

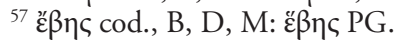

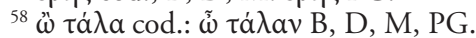

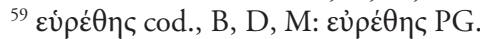




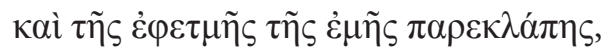

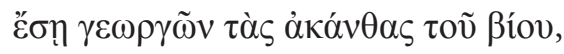

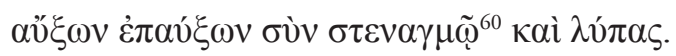

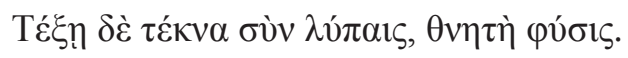

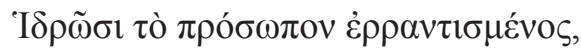

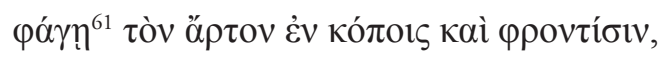

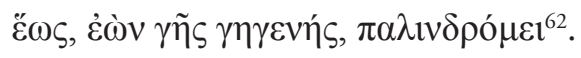

\section{Versos de Ignacio sobre Adán}

Viendo las luchas, combates y peleas

que la reptante víbora a los primeros padres

trenzó, trenzándolos otrora mediante el placer;

y admirando la muy mentada derrota

y recordando ahora la antigua maldición

que encontró la naturaleza de aquellos mortales

al aparecer el enemigo a la eminente lucha ${ }^{63}$,

comprende en ellos tu situación

para estar provisto de lanza en similares trincheras.

Pues cuando vio la naturaleza de los intelectuales

el antes caído dragón, desdichado por la corrupción,

y también la fijación abajo, con inefable velocidad

conducida [aquélla] por la razón y la sola voluntad

cual lo venerable de la herencia en lo alto

-querubines, principados y serafines y tronos,

arcángeles y órdenes de los temibles ángeles,

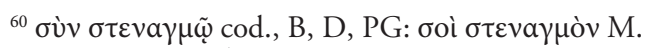

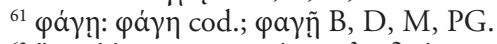

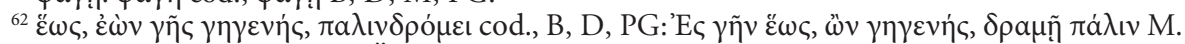

${ }^{63}$ Genitivo objetivo. Dice MÜLLER: "genit. videtur esse localis (“eum e lucta prodiisset”), ut passim invenitur apud veteres poetas.
} 
tierra, cielo y toda posición de los astros, lumbrera que lleva el carro hacia el día y agua y fuego, aire con éter, y otro que ilumina la noche adecuadamente

y bestias, todas las que nadan y la raza de los alados

y todo el mundo manifestado en razón-

y [vio] a este [hombre] tomar, con la mano y la sola ${ }^{64}$

consulta, la existencia del modo más divino, y mostrado cual amo de los subordinados

por ser preferido a todo otro a causa del raciocinio

y considerado digno, por ende, de toda honra,

por ser mostrado según imagen de Dios ${ }^{65}$,

mueve contra él toda contienda por envidia

hasta que se vaya de la región del Edén,

en la que había sido puesto para cultivar plantas y quedarse ${ }^{66}$

y deleitarse por ello con las labranzas.

Era el Edén la admiración de todos los lugares de la Aurora ${ }^{67}$

que muestra, como agua irrigante, una cuadricorriente ${ }^{68}$

partera de todas las plantas ${ }^{69}$,

que conllevan mucha hermosura de encanto

y a toda visión se regalan en demasía.

Estando temeroso el seductor de acercarse a él

como al que ha recibido tales cosas por mano de Dios

y por ello espléndido a la vista,

se acerca a Eva, más lenta por naturaleza

y más sabia para el ataque contra el hombre.

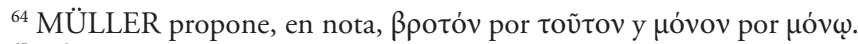

${ }^{65}$ Cf. Génesis 1: 26-27.

${ }^{66} \mathrm{Cf}$. Génesis 2: 15.

${ }^{67}$ Cf. Génesis 2: 8.

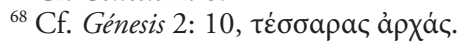

${ }^{69}$ Cf. Génesis 2: 9.
} 
A ésta, para ayuda ${ }^{70}$ y colaboración de la vida, sacando un pequeño fragmento del costado de aquél ${ }^{71}$, la construyó [Dios] y se la dio a él [Adán] muy sabiamente, como don de ensueños y remedio de trabajos;

y procurándoles promesas de mandamientos les encargó la potestad de todas las plantas ${ }^{72}$ mas muy especialmente que para nada tocaran una;

de modo que, si la comían, obtendrían tremendo lote fatal, mas si no quebrantaban su ley vivirían sin penas hasta la buena herencia de los años.

Yendo hacia aquélla y armada de casco, también de nuevo marcha a las lides [la serpiente] y le dice:

\section{Serpiente:}

¿Por qué ¿3 $^{3}$ mujer, os dijo el Plasmador

"No toquéis esta sola planta"?

Lo dijo, celándoos, para que no os hagáis dioses.

Eva:

Afirmó que comiéramos de todo madero

mas que solamente de esta planta evitáramos el gusto,

para que no recibiéramos un lote fatal a cambio de la comida. 60

\section{Serpiente:}

No acojas en tu seso estas cosas, mujer;

pues [Él] sabía que si comíais de este solo madero

seríais realmente como dioses, teniendo buena visión.

Eva:

¿Te dirigiste a Adán, mi marido y patrón?

\footnotetext{
${ }^{70}$ Cf. Génesis 2: 18.

${ }^{71}$ Cf. Génesis 2: 21.

${ }^{72}$ Cf. Génesis 2: 16.

${ }^{73}$ Cf. Génesis 3: 1.
} 
¿O has venido hasta mí animándote a todo, extranjera?

Pues sabes que he recibido el ser natural después que él.

\section{Serpiente:}

Queriéndolo tú, mujer, Adán ninguna fuerza tiene;

pues si lo exhortas, seguirá tus palabras

y lo aceptará muy rápidamente; y comerá contigo.

\section{Eva:}

Te dirigiste realmente a mí como a quien tiene temor

y dices que yo con artimañas lo aflojo ${ }^{74}$ :

iré entonces, si ha de aceptar esto.

\section{Serpiente:}

No te dirijas a tu marido sin degustar:

prueba primera y come primera;

pues así lo persuadirás cayendo bien: pues eres mujer ${ }^{75}$.

Eva:

Me persuadiste para que comiera y para que a mi cónyuge

exhortara a comer, extranjera sugerente,

iojalá alcancemos las esperanzas de las que hablaste!.

\section{Serpiente:}

No des lentas las ${ }^{76}$ promesas.

Como rápidas acogerás las mías, mujer;

pues lo que procede lento no sabe ${ }^{77}$ parir una gracia.

Eva:: [a Adán]

Marido, viendo [tú] lo encantador de esta planta

${ }^{74}$ Cf. Sofocles, Filoctetes 55.

${ }^{75}$ Cf. Eurípides, Andrómaca 85.

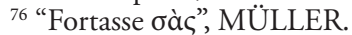

77 “Malim scribi oĩ $\delta a$ vel oĩo $\theta \alpha$ ” MÜLLER. 
complácete ${ }^{78}$ cuanto antes en su degustación y visión.

Acéptala y, si la comieres, te harías divino.

\section{Adán:}

¿Divino ${ }^{79}$ es el don o lo procuró un extraño?

¿Y cómo una degustación me hará dios si de qué modo?

Pues ningún dios hay que participe de alimentos.

Eva:

¿Buscas, amigo, algo mejor que el conocer

la naturaleza de lo bueno y de lo malo en la vida?

$\mathrm{Al}$ participar de éste [fruto] podrías tomar experiencia de ambas cosas. 90

\section{Adán:}

¿Y cómo alguien [estará], traspasando los límites puestos

que el Creador fijó como exactos?

¡Cómo fuiste engañada, desdichada, por el descuido!

Eva:

Tienes como aversiones los límites inquietantes;

a mí achácame la causa que temes

y yo te liberaré totalmente de la deuda.

\section{Adán:}

Listo, ya lo he probado; y veo, mujer, a la corrupción

deslizarse dentro, en mi vientre,

de la cual -lo sé- caerá un tremendo lote fatal.

Eva:

Y consumen, dentro, mi vientre

dolores de parto que recibí por la degustación del madero, de lo cual me ha seducido la malevolente serpiente.

\footnotetext{
${ }^{78}$ MülleR considera participio de infectivo esta forma y pone coma al final de verso.

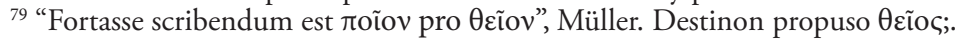




\section{Adán:}

$\mathrm{Al}$ aparecer desnudos, jay!, explícame, mujer, lo de ahora:

¿cubrimos de algún modo la vergüenza? Dime.

Pues veo que no hay abrigo de la vergüenza.

Eva:

Ásperas son estas hojas de higuera, como ves.

Con ellas cubramos la vista de la vergüenza;

pues nos caerá áspera ahora la vida.

\section{Adán:}

Conociste un poco tarde lo tremendo de las faltas

y ahora te das cuenta del castigo dado:

acoge, por cierto, el provecho de las acciones.

Eva:

Reconozco que desvié la mente de modo insensato

y corrompí sin querer tus sesos, esposo;

de ahí que he sido señalada como causante de la corrupción.

\section{Adán:}

¿No percibes, oh mujer, con los oídos un fragor

golpeado de lo alto, como desde Dios?

¡Preveo con temor el castigo de lo hecho!

\section{Eva:}

Se presenta a los oídos el estrépito de los pies de Dios ${ }^{80}$;

temiendo soportar su franqueza,

me parece mejor, amigo, ocultarme contigo.

Adán:

¿Qué lugar me ocultará? ¿Y seré ocultado?

Pues ningún lugar hay, fuera de Dios,

en el que al huir me esconda. Con todo, sígueme, mujer.

${ }^{80}$ Cf. Eurípides, Ifigenia en Áulide 438. 


\section{Dios:}

Adán, el sobresaliente de todas las creaturas,

la preocupación y adquisición de mi mano,

¿adónde ahora marchaste? ${ }^{81}$ ¿Y cuál eres en lugar de tal? ${ }^{82}$

\section{Adán:}

Tus palabras y pies no dejan que estando

desnudo vaya ante tu vista ${ }^{83}$; pero por cierto

es tremenda la huida y el miedo me lo impide.

\section{Dios:}

¿Quién, jay, desdichado!, extravió ahora tus sesos

e indica ${ }^{84}$ entonces la desnudez para verla, si no te dirigiste a lo que no es lícito dirigirse?

\section{Adán:}

Persuadido por la mujer que me has dado, Plasmador, que comporta por el decir mucha persuasión, me dirigí al madero del que no era lícito comer ${ }^{85}$.

\section{Dios:}

Dado que te hallas vencido por la mujer ${ }^{86}$

y te desviaste ${ }^{87}$ de mi prescripción, estarás labrando los cardos de la vida, aumentando y aumentando incluso penas con gemido.

[A Eva:] Parirás hijos con penas, naturaleza mortal.

[A Adán:] Rociado en el rostro por sudores ${ }^{88}$,

${ }^{81}$ Cf. Génesis 3: 9.

${ }^{82}$ Cf. Sofocles, Ayante 923.

${ }^{83}$ Cf. Génesis 3: 10. Cf. Sofocles, Edipo en Colono 1440.

84 "Forsan $\delta \varepsilon \dot{i} \kappa v v \varepsilon v$ ", MÜLLER.

${ }^{85}$ Cf. Génesis 3: 12.

${ }^{86}$ Cf. Eurípides, Alceste 697.

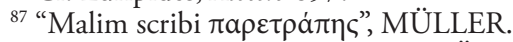

88 "Fort. í $\delta \rho \tilde{\omega} \tau$ I... sec. Gen. 3,19", MÜLLER. 
comerás ${ }^{89}$ el pan entre cansancios y preocupaciones

en tanto que, siendo nacido de la tierra, retornas a la tierra ${ }^{90}$.

En principio, podemos señalar que la estructura del poema puede ser armada de este modo:

Prólogo (1-54)

Primer episodio: Serpiente-Eva (55-81)

Segundo episodio: Eva-Adán (82-123)

Tercer episodio: Dios-Adán (124-135)

Éxodo: Dios (136-143)

El prólogo está a cargo de alguien innominado, posiblemente la voz del autor. En la tragedia clásica, un dios (Hermes en Ion de Eurípides; Posidón y Atenea en Troyanas) o un personaje (el vigía, en Agamenón de Ésquilo; Eteocles y el Mensajero en Siete contra Tebas; Etra en Suplicantes de Eurípides; Anfitrión y Mégara en Heracles) se ocupaba de presentar el asunto y destacar aquellos aspectos en los que la pieza pondría el acento. En los vv. 1-9 de este prólogo, se plantea el ejemplo de la tentación del diablo como modo de que el tú-destinatario "comprenda la situación” para tener las armas adecuadas en ocasión similar. Se revela, pues, una intención claramente didáctica en el orden de lo espiritual.

Vv. 10-33: el prologuista explica que la motivación de la serpiente o dragón es la envidia: el diablo, rebelde, cayó al infierno y ve, en cambio, que la naturaleza del hombre, hecha a imagen y semejanza de Dios, queda exaltada por la razón y la voluntad como ama de toda la creación.

Vv. 33-37: describe el Edén, es decir, el ambiente en que se desarrolla el drama; por su belleza resulta contrastante con el final y, de tal modo, se acentúa lo 'trágico' del asunto.

Vv. 38-42: plan de ataque; la serpiente recurrirá a la mujer como intermediaria.

Vv. 43-52: hace reseña de la creación de Eva, creada por Dios para ayuda del varón, y del mandato de no probar un fruto, 'el árbol del conocimiento del bien y del mal'.

${ }^{89} \varphi$ áyouaı es futuro tardío de $̇ \sigma \theta i ́ \omega$. No hace falta enmendar. Cf. Spt Génesis 3: 17.

${ }^{90}$ Cf. Génesis 3: 14-19. 
Vv. 53-54: este dístico introduce el primer episodio. Era frecuente en el drama antiguo, por convención, que un personaje anunciara la llegada de otro y diera alguna referencia sobre él. Por ejemplo, en Persas 150 ss. de Ésquilo, el corifeo, al final de la párodo, anuncia la llegada de Atosa; en Siete contra Tebas 369 ss. el corifeo anuncia la entrada del Mensajero y de Eteocles.

Lo que consideramos primer episodio es el diálogo entre la serpiente y Eva. Tanto este episodio cuanto los restantes están armados consistentemente con breves $\dot{\eta} \sigma \varepsilon 1 \varsigma$ de tres versos cada una. La serpiente afirma que Dios prohibió el árbol para que el ser humano no pudiera hacerse dios. La mujer replica que la amenaza fue tener un destino negativo. Eva se dirige a la serpiente como "extranjera", alguien extraño al lugar y a la naturaleza de ella y de su marido. Enseguida pregunta si Adán, que tiene precedencia respecto de ella, ya sabe lo que sostiene la serpiente. Eva acepta la lisonja de la serpiente, quien afirma que el hombre la obedecerá, pero conviene que ella pruebe primero el fruto. Ella cree que se cumplirá lo dicho por la serpiente, que la exhorta a actuar con rapidez. En este episodio tenemos dos elementos clave de la tragedia: la úßpı en tanto pretensión de exceder la propia naturaleza; la $\alpha \mu \alpha \rho \tau i ́ \alpha$, por cuanto Eva cae en el error de confiar en las promesas de la seductora.

En el segundo episodio, Eva dialoga con Adán. Ella reitera la promesa de la serpiente y él alega argumentos racionales en contra: un extranjero no puede dar un don divino y no se puede ser dios si se come. Cabe seńalar que el argumento de Adán responde a que tanto en la concepción judeo-cristiana (Dios inmaterial, que no come) cuanto en la griega politeísta (dioses que tienen ícor en vez de sangre, beben néktar y comen sólo ambrosía 'lo que hace inmortal'), la divinidad no necesita de alimento. Eva alega que el comer puede darles conocimiento de lo bueno y de lo malo, cosa que la serpiente no había mencionado: el dato surge del trasfondo bíblico, conocido por el público. Adán critica que la mujer se haya dejado convencer contra el mandato del Creador. Ella, con clara soberbia, sostiene que podrá liberar a Adán de la culpa. Se produce la $\pi \varepsilon \rho \imath \pi \varepsilon ́ \tau \varepsilon ı$. Él se deja persuadir y de inmediato observa las consecuencias: la corrupción del cuerpo, el dolor físico, la conciencia de desnudez, el miedo al castigo. Hay una

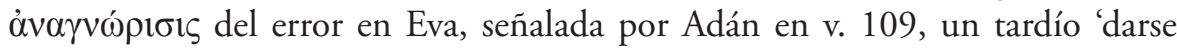
cuenta' del error y del exceso, que él censura con sarcasmo ("acoge el provecho de las acciones"). Ella se reconoce culpable. Ante la cercanía de Dios, se esconden, sabiendo que es inútil ocultarse de Él. 
El tercer episodio, breve, es el diálogo entre Dios y Adán. Dios lo interroga como si no supiera lo ocurrido, pero Adán confiesa de inmediato.

El éxodo quiebra la estructura formal; ya no hay diálogo con pequeñas

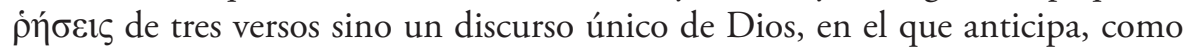
consecuencia de la soberbia desobediencia, el dolor del trabajo para el hombre, el dolor del parto para la mujer, el cansancio y las preocupaciones que caracterizarán la vida humana hasta la muerte, aludida como 'retorno a la tierra'. La serpiente no aparece ni Dios le habla, cosa que sí ocurre en Génesis 3: 14-15

La versificación del poema intenta acercarse a uno de los metros típicos del drama clásico: el trímetro yámbico. Se sabe que en época bizantina, en que ya no se reconocen las cantidades vocálicas, este verso tomó la forma del llamado "dodecasílabo" en razón de que, habitualmente, se construye con doce sílabas que representan los seis pies yambos del trímetro: las 'disoluciones' son poco frecuentes. En el trímetro clásico, la breve puede ser reemplazada solamente en los pies impares, es decir, en el primer pie de cada metro (sílabas primera, quinta y novena); en los pies donde la breve es obligatoria (sílabas tercera, séptima y undécima), el dodecasílabo recurre a las vocales gráficamente 'breves', es decir, epsilón y omicrón, o a las vocales que eran gráficamente indefinidas, alfa, iota e ypsilón; cuando debe haber vocal larga, se recurre a la eta y a la omega o a las vocales indefinidas. Los diptongos pueden funcionar como breves (sobre todo los que conllevan iotacismo) y las reglas de las vocales trabadas por doble consonante y de vocal ante vocal no siempre se aplican. El dodecasílabo tiene una cesura en la quinta o la séptima sílabas; sólo hay hiato ante cesura; también ante ella se admite brevis in longo.

Teniendo en cuenta esto, el análisis de la versificación del poema arroja como resultado:

- la doble consonante traba en v. $1 \pi \alpha \lambda \alpha i ́ \sigma \mu \alpha \tau \alpha \beta \lambda \varepsilon ́ \pi \omega v ;$ v. 2 ó $\pi \rho о \sigma \varepsilon \rho \pi v ́-$

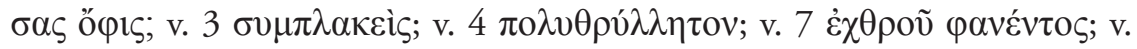

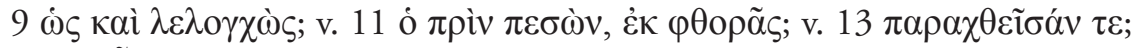

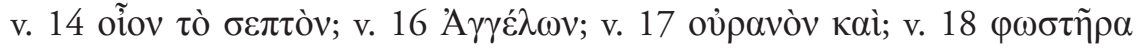

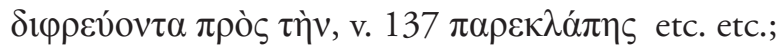

${ }^{91}$ BROWNING (1968: 405) señaló que hay "un prologue, des entrées et sorties, des dialogues (...); il y a une vraie péripétie, car la situation des principaux personnages est bien différente à la fin de ce qu'elle était au commencement". 


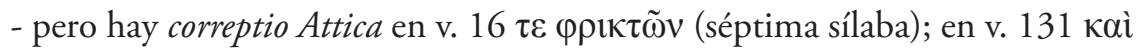

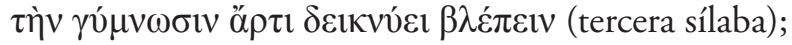

- hace algunas sustituciones de yambo por espondeo donde es regla: v. 2

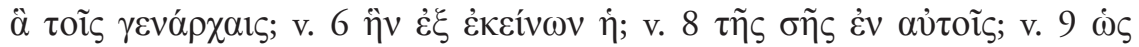

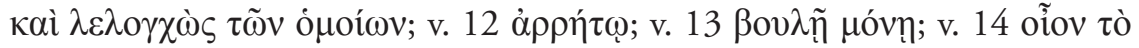

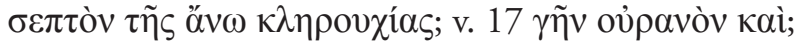

- hace uso de la última sílaba ỏoí́ $\varphi$ opos, por ej. en 19, 21, 22, 50, 51, 59, $60,63,65,72,73,74,85,88$, etc.;

- suele respetar la cantidad incluso en las vocales 'gráficamente indiferentes'; por ejemplo $\pi \alpha ́ \lambda \eta \varsigma$ (v. 7) tiene alfa breve en séptima sílaba; en la penúltima, siempre usa omicrón y epsilón para los timbres $o$ y $e$;

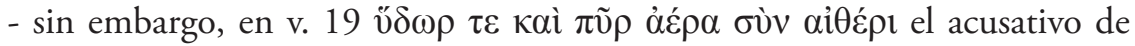
áń $\rho$ tiene alfa breve en sílaba larga obligatoria (la octava); dos veces en el mismo verso 102 recurre a la 'indiferencia' de la alfa: $\dot{\varepsilon} \xi$ oṽ $\mu \varepsilon \pi \alpha \rho \eta ́ \pi \alpha \varphi \varepsilon$

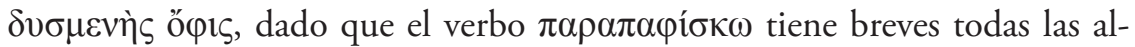

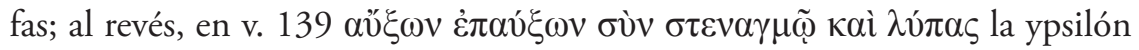
de $\lambda \hat{v} \pi \alpha$ es larga en sílaba breve obligatoria (undécima) y se reitera la licen-

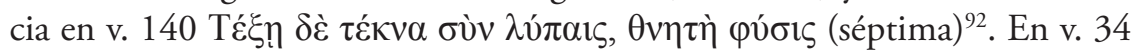

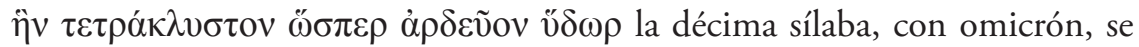
trabaría con el espíritu áspero para funcionar como larga, recurso clasicista.

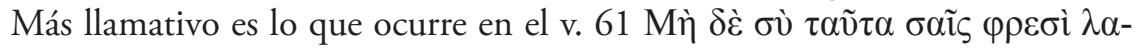
ßoṽ, yúval, donde la -1 es 'indiferente' pero la epsilón no; lo mismo sucede al

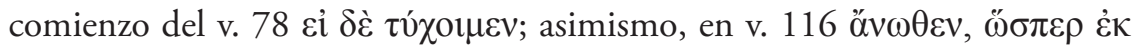

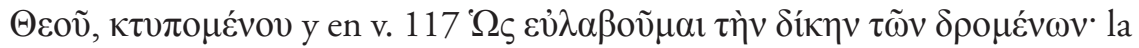
omicrón aparece, en ambos casos, en sílaba larga obligatoria. Estas 'licencias'

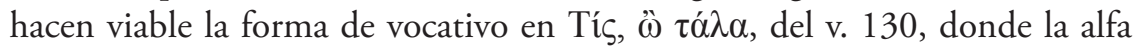
podría mantener la condición larga del nominativo clásico o funcionar como

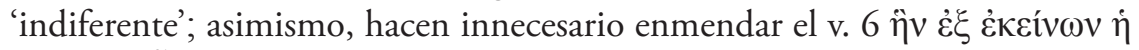

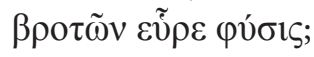

- a necesidades métricas responde la morfología de $\tilde{\omega} \omega \varsigma$ en vv. 30 y 143 y de દ̇òv en v. 143;

${ }^{92}$ MÜLLER (1886: 32) señala que ambas ypsilones se abrevian inusitadamente. 
- en v. $35 \mu \alpha \imath \varepsilon v ́ \tau \rho ı v$ infringe la regla del paroxítono final, por lo que B propuso $\mu \alpha \imath \varepsilon v \tau \rho i ́ \alpha v$; lo mismo ocurre en v. 96 ỏ $\varphi \lambda \eta ́ \mu \alpha \tau o s$, que Müller propuso

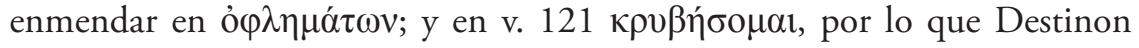
propuso la enmienda $\pi \tilde{\eta} \kappa \rho v \beta \eta \sigma o ́ \mu \varepsilon \theta^{\prime}$; y Boissonade sugirió alterar el orden

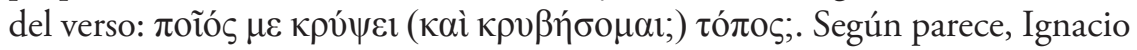
es laxo en este aspecto.

Por lo tanto, la métrica del dodecasílabo, si bien no presenta ninguna disolución, se ajusta bastante a la forma clásica; las licencias son proporcionalmente escasas.

El Coro era elemento esencial de la tragedia (y de la comedia) clásica; sin embargo ya había decaído en el período postclásico. En el siglo IV, así como en la comedia el coro pasa a entonar embólima, cantos de contenido general, con temas como el hado, la fortuna, la hýbris, a tal punto que a veces ni se transcriben los textos en los manuscritos, parece que tampoco en la tragedia tuvo mucho peso el coro. Reso, la pieza pseudo-euripidea que puede datarse a mediados del siglo Iv (en esa época aparecen representaciones de la muerte del personaje iliádico), sí tiene un coro con cantos propios y participación activa: puede ser un último ejemplo del uso 'clásico' o una reacción clasicista. También en Héctor de Astidamante hay una $\emptyset \delta \eta ́$ atribuible a un coro. Pero su peso es tan menor que por eso hay pocos títulos que aludan al coro: prevalece

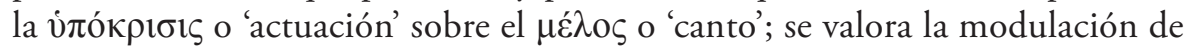
la voz del actor, su histrionismo que dé verosimilitud, que muestre agitación, llanto, sudor. En fin, no debe extrañar que en una pieza bizantina no haya coro cuando éste llevaba siglos desaparecido, si bien algunas piezas clasicistas lo recrean.

La cantidad de actores que se necesitan para este 'drama' es de sólo tres, de acuerdo con la antigua regla. Un actor A podría representar a Eva; un actor B, al prologuista y a Adán; y un actor $\mathrm{C}$ a la Serpiente y a Dios. El reptil puede estar caracterizado como tal, cosa común en el teatro clásico, donde solía haber coros animalescos. Adán y Eva pueden aparecer 'falsamente' desnudos, así como ocurría en las comedias aristofánicas, en las que se cree que las mujeres (actrices mudas) aparecían con mallas. Asimismo, Dios puede ser una voz en off, muy eficaz, mientras los actores hacen la éxodos.

La escenificación no ofrecería problemas, dado que se requiere la imitación de un jardín y la presencia de al menos un árbol con frutos. 
No sería extraño que el drama fuera representado como una forma de 'ambientación espiritual' en el período de Cuaresma, como aún hoy se dramatizan en las calles la via crucis en Semana Santa o el pesebre en Adviento. La rúbrica ańadida al texto ("para un amigo caído en desgracias") no parece ajustarse mucho al asunto, salvo que se quiera decir al "amigo" que todo mal es fruto del pecado original ${ }^{93}$. De todos modos, aunque la composición pueda haber sido aplicada a una persona en particular, no se excluye una aplicación pastoral más amplia.

Pensamos que en la concepción bizantina del teatro este drama es una 'tragedia', no como lo fue en sus orígenes ni en el siglo v ni en la época postclásica ni en la helenística; sino una forma diferente, pues nunca la tragedia griega fue monolítica, ni siquiera entre los grandes autores del período clásico. En este caso, se trata de una 'tragedia religiosa' al modo esquileo, con $v \beta \rho ı \varsigma, ~ \alpha \mu \alpha \rho \tau i ́ \alpha$,

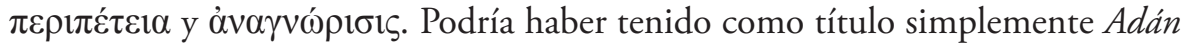
o Adán y Eva, como solía ocurrir en la tragedia clásica; pues hay un personaje trágico, el ser humano representado por Adán y Eva, que a sabiendas de lo que le espera, caído de su estado de seguridad y felicidad, enfrenta a Dios ${ }^{94}$. No hay happy end, como aparece en algunas tragedias euripideas; posiblemente podía haberlo en una tragedia que representara la redención. Claro que el 'canto' se reduce al recitativo del verso rítmico: no hay intervención lírica de un coro. No se trata, pues, de un $\tau \rho \alpha \gamma o v ́ \delta$ sino de una $\tau \rho \alpha \gamma \omega \delta i ́ \alpha$ adaptada al mundo bizantino.

\footnotetext{
${ }^{93}$ MÜLLER (1886: 28) vincula esto con el v. 9.

${ }^{94}$ Sobre estos rasgos de la tragedia 'clásica', cf. LESKY (1970, introducción).
} 


\section{Referencias bibliográficas}

Browning, R. (1968). "Ignace le diacre et la tragédie classique à Byzance”, Revue des études grecques 81, 401-411.

Cantarella, R. (2010). Poeti bizantini, a cura di Fabrizio Conca, Milano, BUR Rizzoli, $3^{\mathrm{a}}$ ed.

Cottas, V. (1931). Le théâtre à Byzance, Thèse Lettres, Paris, Geuthner.

DE Boor, C. (1888). "Der Epigrammendichter Ignatius”, Hermes 23, 149-152.

Dimitrakos, D. (1951). Méga léxikon ólis tis ellinikis glóssis, Athinai, Domi.

DüBner, F. (1846). Christus patiens, Ezechieli et christianorum poetarum reliquiae dramaticae, en F. Wagner, Fragmenta Euripidis iterum edidit, perditorum tragicorum omnium nunc primum collegit F. Wagner, Paris, Didot.

Efthymiadis, S. (2011). "Hagiography from the 'Dark Age' to the age of Symeon Metaphrastes (eight-tenth centuries)", en The Ashgate research companion to Byzantine hagiography, vol. I, Farnham-Surrey, Ashgate, 95-142.

Kazhdan, A. (1999). A history of Byzantine literature, edited by $\mathrm{Ch}$. Angelidi, Athens.

Krumbacher, K. (1897). "Ignatios, Diakon in Konstantinopel", en Geschichte der byzantinischen Litteratur, München, Beck, 716-720.

La Piana, G. (1936): “The Byzantine theatre”, Speculum 11/2, 171-211.

Lesky, A. (1970). La tragedia griega, Barcelona, Labor.

Marenghi, G. (1957). "Ignazio diacono e i tetrastici giambici", Emerita 25, 487-492.

Migne, J. (1894). Patrologiae graecae cursus completus, vol. CXVII, Paris, Garnier.

Müller, C. (1886): ed. Ignatii Diaconi tetrasticha iambica 53, versus in Adamum 143, Kiel.

Wolska-Conus, W. (1970). "De quibusdam Ignatiis", Travaux et mémoires, 4, 329-360. 